\title{
O que Significa o Desmonte? Desmonte Do que e Para Quem?'
}

\author{
Camilla Fernandes Marques ${ }^{1}$ \\ ${ }^{1}$ Universidade Católica Dom Bosco, MS, Brasil. \\ Hebe Signorini Gonçalves ${ }^{3}$ \\ ${ }^{3}$ Universidade Federal do Rio de Janeiro, RJ, Brasil.
}

\author{
Nathalia Leardini Bendas Roberto ${ }^{2}$ \\ ${ }^{2}$ Universidade Estácio de Sá, RJ, Brasil. \\ Anita Guazzelli Bernardes ${ }^{4}$ \\ ${ }^{4}$ Universidade Católica Dom Bosco, MS, Brasil.
}

Resumo: $\mathrm{O}$ artigo tem como objetivo discutir o desmantelamento das políticas públicas, em específico, das políticas de saúde e da assistência social. A discussão situa-se no campo da Psicologia Social e inspira-se no pós-estruturalismo para análise desta problemática, tendo como questionamento norteador como se constitui o desmonte, considerando-o como processo dinâmico e inerente à produção das políticas. Por meio do método cartográfico, foi possível percorrer materialidades que emergem como pistas para compreender tal processo. Entende-se que há uma tensão na própria construção dessas políticas, com o intuito de substituir modelos anteriores que não se extinguem pela incorporação do SUS e do SUAS à Constituição. Esta se caracteriza pelo esvaziamento de conceitos norteadores das políticas, como as noções de território e vulnerabilidade. Esse esvaziamento potencializa a emersão de uma nova lógica de governo dentro das políticas públicas, não somente por via da regulação, normatização das condutas e criminalização de certa categoria da população, mas também por uma necropolítica, que visa a colocar no jogo democrático uma política de morte.

Palavras-chave: Desmonte, Políticas públicas, Necropolítica, SUS, SUAS.

\section{What Does Dismantling Mean? Dismantling of What and for Whom?}

\begin{abstract}
This paper aims to discuss the dismantling of public policies, particularly those related to health and social assistance. With a post-structuralist inspiration, and situated in the field of Social Psychology, this discussion questions how that dismantling has occurred, considering it as a dynamic process that is inherent to the production of policies. By means of the cartographic method, it has been possible to address materials that have emerged as hints to understand that process. There is a tension in the very formulation of those policies aiming at replacing previous models that have not been extinguished with the incorporation of SUS and SUAS to the Constitution. The latter is characterized by the emptying of guiding concepts of those policies, such as the notions of territory and vulnerability. This emptying potentiates the emergence of a new governmental logic within the public policies, by means of not only regulation, conduct normalization, and criminalization of a certain population category, but also through necropolitics, aiming at introducing a death policy in the democratic game.
\end{abstract}

Keywords: Dismantling, Public policies, Necropolitics, SUS, SUAS.

\footnotetext{
${ }^{1}$ Agradecimentos: CNPq e CAPES.
} 


\title{
¿Qué Significa el Desmontaje? ¿Desmontaje Qué y para Quién?
}

\begin{abstract}
Resumen: El artículo tiene como objetivo discutir el desmantelamiento de las políticas públicas, específicamente las políticas de salud y de asistencia social. La discusión se ubica en el campo de la Psicología Social y se inspira en el postestructuralismo para el análisis de este problema, teniendo como cuestionamiento orientador cómo se constituye el desmantelamiento, considerándolo como un proceso dinámico e inherente a la producción de políticas. A través del método cartográfico, fue posible transitar por materialidades que emergen como pistas para comprender este proceso. Se entiende que existe una tensión en la propia construcción de estas políticas, para sustituir modelos anteriores que no se extinguen por la incorporación del SUS y del SUAS a la Constitución. Esto se caracteriza por el vaciado de los conceptos que orientan las políticas, como las nociones de territorio y vulnerabilidad. Ese vacío potencializa la emergencia de una nueva lógica de gobierno dentro de las políticas públicas, no sólo mediante la regulación, normalización de conductas y criminalización de una determinada categoría de la población, sino también a través de una necropolítica, que busca colocar una política de muerte en el juego democrático.
\end{abstract}

Palabras clave: Desmontaje, Políticas públicas, Necropolítica, SUS, SUAS.

Este texto é produto da reflexão em comum de pesquisadoras que têm se preocupado em colocar em exame as práticas da Psicologia a partir de acontecimentos do cotidiano. As quatro vozes que falam aqui encontram a produção de uma rede de pesquisadores do campo da Psicologia com alvo nas mesmas questões. Assim, embora falem a partir de um lugar específico e particular, as autoras querem ecoar algo que há certo tempo tem ocupado a produção em Psicologia: a violência, as territorialidades, as políticas e seus impactos sobre as subjetividades.

Problematizar essa dupla articulação - dos temas, no campo das práticas sociais, e dos textos, no campo da produção acadêmica - permite-nos situar (Haraway, 1995) o presente, o atual cenário brasileiro, sobretudo nos últimos quatro anos. Entendemos que nesse período as ações governamentais têm continuamente acirrado um processo de desmantelamento das políticas sociais públicas, em um movimento que dialoga com os princípios da necropolítica, desmontando estratégias que pensávamos asseguradas no e pelo Estado de Direito. Essa política de morte, que recrudesceu no período mencionado, traduz-se em um desinvestimento violento nas condições para viver, o que acelera e intensifica as distintas formas de desigualdades sociais.

Problematizar os cenários de desmonte das políticas sociais nos anos recentes implica conside- rar também o modo como a Psicologia pode ocupar esses territórios, de modo a deixarmo-nos interpelar. As políticas sociais configuram um espaço político que nos possibilita constituirmo-nos como sujeitos, pensarmo-nos enquanto sujeitos da Psicologia e, sobretudo, arriscarmo-nos a operar com a Psicologia frente à produção de desmontes, violências, desproteções, vulnerabilidades. Por isso, a pergunta que nos norteará no texto é: o que significa o desmonte das políticas públicas e como ele tem se realizado? Ao pensarmos a palavra desmonte de modo concreto e ao mesmo tempo amplo, buscamos focar algo que tem certa montagem, mas que está em processo de separação de seus componentes/peças. Na tentativa de construir essa problematização, também nos questionamos sobre o que queremos ao interrogarmo-nos sobre o processo de desmonte. Certamente, não visamos à representação de um objeto, muito menos à sua criação. De que se trata, então, no cenário atual brasileiro, tomar o desmonte como algo que nos interpela?

Podemos iniciar por este elemento e tomar o desmonte como um disparador. Dito de outra forma, tomamos os anos recentes como tempos de desmonte e assumimos o próprio desmonte como fio condutor para o entendimento não apenas dos propósitos não anunciados das políticas públicas, como também das próprias políticas, da sua lógica em curso e do lugar 
da Psicologia nessa cena. Para tanto, voltamo-nos para os discursos e as práticas cotidianas do cenário brasileiro, inicialmente identificando as articulações que possibilitam falar do desmonte e das condições que permitiram e permitem sua emergência. Nesse processo, tentaremos evidenciar as peças que estão sendo des-unidas ou des-articuladas, para compreender o que o desmonte implica e quais são seus efeitos.

Essas interpelações são apenas movimentos iniciais do pensamento de um grupo que há largo tempo tem trabalhado no campo das políticas públicas de saúde e assistência social. Com essa afirmação, demarcamos desde já os processos sobre os quais este texto procura refletir. Com esses primeiros disparadores, tensionamos práticas cotidianas na composição e na análise de um campo problemático que se apoia na Psicologia Social e se inspira em vetores de análise pós-estruturalistas.

\section{Sobre as des-montagens das políticas}

As políticas públicas constituem-se em um processo dinâmico de montagem e desmontagem. A despeito de nossa ainda incipiente democracia, essa processualidade resulta da própria participação social. As políticas que pretendemos colocar em análise - a Saúde e a Assistência Social - são, elas mesmas, resultado desse montar e desmontar incessante, próprio do jogo democrático. Trata-se de considerá-las em jogo democrático, pois elas respondem a demandas e dizem respeito a processos que não se estabilizam, tampouco asseguram a democracia; são, antes, sistemas que se constituíram, ao longo dos últimos 30 anos, a partir de uma rede complexa de lutas. Essas lutas, por sua vez, dão-se por procedimentos heterogêneos e controversos que, frente à atual investida neoliberal pela qual o país passa (Bernardes, \& Guareschi, 2008), implicam a fragilização crescente de alguns avanços, especialmente daqueles voltados para grupos sociais vulneráveis, nos quais se pretendia imprimir alguma modalidade de ascensão social, possibilitando acesso a condições de vida mais dignas.

O desenho original de ambas as políticas oficiais - Saúde e Assistência Social -, em que pesem suas especificidades, vem contrapor a organização anterior, já que se inaugurou com base nos princípios da universalidade e da garantia de direitos. Sabemos também que, em sua proposta, se distanciam em muito da hegemonia neoliberal, que prega a competitividade e a individualização. Tensionando o pas- sado e o futuro, a formulação dessas políticas enfrentou um campo pouco favorável à sua consolidação. Consideramos que esses embates estão na base do desmonte em curso, perceptível na desarticulação de peças importantes: redução de financiamento, precarização do trabalho e emendas constitucionais que restringem direitos, sob o argumento de exigências da segurança pública.

Os princípios em torno dos quais essas políticas se organizam estão inscritos no texto constitucional, mas a Constituição, per si, não assegura a democracia. Temos acompanhado inúmeras Propostas de Emenda Constitucional (PEC) que desfiguram o desenho proposto para as políticas sociais e flertam com a eliminação real ou simbólica de sujeitos, grupos e segmentos: exemplos disso são as formas de operacionalização das noções de território e vulnerabilidade, já discutidas em alguns artigos e estudos (Cruz, \& Hillesheim, 2016; Hillesheim, \& Cruz, 2008; Hüning, \& Scisleski, 2018). Destacamos, em especial, a PEC $n^{\circ} 241 / 2016$, deferida como PEC $n^{\circ} 55 / 2016$ no Senado e legitimada como Emenda Constitucional $n^{\circ} 95 / 2016$, que congela por 20 anos os investimentos em políticas públicas nas áreas de saúde, educação e assistência social.

As políticas sociais, em seu desenho constitucional original, podem ser compreendidas como a tentativa de produção de uma biopolítica focada nos territórios e nas vulnerabilidades como formas de resposta e investimento na vida. Entretanto, será por intermédio desses mesmos princípios - território e vulnerabilidade - que a produção de morte encontrará condições de emergência. Um dos elementos privilegiados para essa remodelagem é a submissão da biopolítica à segurança. Esta, apoiada na lógica do inimigo, endossa ações que leem certas vulnerabilidades como risco e transformam certos territórios em zonas de guerra, onde a morte é admitida e o assassinato é consentido ou minimizado (Noguera, 2018).

Por isso, apostamos que os conceitos de território e vulnerabilidade, norteadores de ambas as políticas, podem ser tomados como importantes vetores de análise para o desmonte que intencionamos examinar. Dada a centralidade desses conceitos nas políticas em análise, propomo-nos a desfiar os sentidos que sustentam sua discursividade democrática: quais articulações tornam possível sua utilização como orientadores das políticas de saúde e assistência? A que eles respondem no jogo democrático? Quais 
linhas de poder eles compõem? Quais composições e recomposições colocam em movimento?

\section{Das composições das políticas: território e vulnerabilidade}

Território e vulnerabilidade são conceitos sobre os quais as políticas sociais se articulam. Eles são elementos orgânicos das políticas, organizando aspectos operacionais, priorizando e direcionando as ações; ou seja, foram incorporados tanto à concepção quanto aos princípios de execução da assistência social e da promoção da saúde. São conceitos-superfície que criam planos materiais a partir dos quais as ações se desenvolvem. Entendemos que, se ambos são conceitos centrais na montagem das políticas, então, o percurso que permite problematizar seu desmonte deve perseguir necessariamente esses mesmos pilares, agora pelo avesso: qual seria sua concepção original e como ela vem se transformando de maneira a permitir o trânsito da biopolítica à necropolítica?

No primeiro momento, uma das formas pelas quais o conceito de território emerge no campo das políticas públicas remete à base geográfica que organiza o sistema, cujos serviços devem estar próximos da população e localizados em regiões de maior incidência de risco e vulnerabilidade (Resolução do CNAS $\left.\mathrm{n}^{\circ} 130,2005\right)$. Espaço foi a primeira categoria utilizada pelo campo da Saúde, inicialmente empregada nos estudos epidemiológicos para evidenciar o local onde a doença e a morte de indivíduos ocorriam, o que permitiria compreender suas relações causais e identificar os riscos à saúde das populações locais; a seguir, houve uma inflexão para o conceito de território, que passou a orientar a organização do cuidado em saúde. Nos últimos 20 anos, o uso do território tem se dado de forma distinta:

Território corresponde tanto à base material de suporte à vida quanto ao espaço de representação das relações em sociedade. Por meio desse uso, é possível identificar e explicar os problemas e as necessidades de saúde e os conflitos decorrentes da apropriação e do uso do espaço pelos atores sociais. Permite compreender a conformação de contextos (político, econômico, cultural, ambien- tal) que expressam, de um lado, potencialidades locais e, de outro, riscos e vulnerabilidades à saúde e ao ambiente (Gondin, \& Monken, 2018, p. 161).

O conceito de território é, portanto, marcado pela sua multiplicidade, e sua variação incide também nas práticas derivadas de suas concepções. Na nossa "montagem democrática", esse conceito tem marcado a organização das políticas, encontrando especial importância na estruturação do planejamento, implementação, execução, avaliação e monitoramento da saúde e da assistência social. O conceito de vulnerabilidade, por sua vez, incorpora sentidos às concepções de território, bem como outras diretrizes na orientação do planejamento das ações dos referidos campos.

Na política de assistência social, o território é tomado como um modo de organização e esquadrinhamento do espaço para o desenvolvimento estratégico dos aparatos da assistência, na tentativa de universalizar a cobertura. Nesses termos, estabelece estratégias de planejamento e monitoramento de serviços socioassistenciais especialmente direcionados a áreas de maior vulnerabilidade (Brasil, 2008). É nessa articulação entre território e vulnerabilidade que o objetivo da política opera a proteção social e a garantia de direitos, além de produzir determinados sujeitos, quais sejam: o usuário da política, o sujeito em situação vulnerável, a família enquanto elemento de governo da vida, dentre outros que organizam uma rede de pensamento, compreensão e apreensão da vida. O território, assim, permitiria acessar as vulnerabilidades de forma situada e responder a elas em suas particularidades, de modo a articular acesso e equidade.

\section{Destrinchando as composições: as linhas de montagem/desmontagem das políticas}

Para considerar as formas de montagem/desmontagem das políticas a partir dos conceitos de território e vulnerabilidade, partimos de uma narrativa de 2016, da experiência no campo da assistência social, que nos leva ao encontro de uma jovem de 19 anos, artista de rua, ocupação/profissão que fez com que fosse acionado o Serviço Especializado de Abordagem Social (SEAS) ${ }^{1}$, ligado à Proteção Social

\footnotetext{
${ }^{2}$ O SEAS tem por finalidade identificar, por meio de busca ativa no território, isso assegurar o trabalho social e a não incidência de violações de direitos por diversas situações, mediante ações programadas e continuadas, promovendo o acesso à rede de serviços socioassistenciais e outras políticas públicas na possibilidade da garantia dos direitos.
} 
Especial da Secretaria Municipal de Assistência Social. O exercício da atividade laborativa, descrita pela jovem como arte de rua, talvez tivesse passado despercebido, não fosse pela presença de seu filho de sete meses em um carrinho, que era deixado sob uma grande árvore em uma das principais avenidas da cidade. A visibilidade do local servia a uma dupla função: de um lado, colocava a artista de rua em local que lhe permitia auferir maior ganho; de outro, expunha a mãe e a criança. Apontamos aqui as estratégias de montagem do território pela política: monitoramento de regiões de vulnerabilidade, entendidas como áreas de incidência de risco, tomadas como regiões prioritárias para a proteção social e a garantia de direitos (no caso, indicando risco e vulnerabilidade para a criança). O trabalho da mãe, nessa linha de interpretação da política de assistência, produziria a exposição da criança à negligência, à exploração e à violência, violando o artigo $5^{\circ}$ do Estatuto da Criança e do Adolescente (Brasil, 1990) e exigindo o encaminhamento da jovem e seu filho ao Centro de Referência de Assistência Social (CRAS).

Entendemos que esta captura pelos dispositivos de monitoramento da política ilustra o contato com o poder (Foucault, 2003). Esse contato ilumina a vida da jovem e torna visível uma modalidade de existência que não cabe nos territórios-existência da política, borrando as fronteiras que definem seus usuários, em consequência definidos como "em situação vulnerável”. Ao rótulo de vulnerabilidade que a política lhe quer impor, a jovem contrapõe-se: ela se identifica como mochileira (viajante independente), artista e artesã de rua, definindo-se assim como profissional e trabalhadora; anuncia a dedicação para com seu filho, "a fralda do [filho][está] em primeiro lugar", acrescentando que "só trabalh[a] de manhã, porque de tarde o sol é muito quente para ficar andando com [s]eu filho"; acusa a falta de recursos institucionais, argumentando que "só lev[a] ele junto [ao trabalho de rua] porque não tem vaga no CEINF [Centro de Educação Infantil] e, se arrumar para ele agora não vai adiantar, porque, daqui uns três ou quatro meses, já v[ai] para outra cidade"; mostra que a atenção para com o filho orientou decisões relevantes em sua vida, ao afirmar que "não f[oi] embora com o pai dele, porque ele [o filho] ainda era muito pequeno para viajar", e que o "mínimo que [tira] [aqui] é $\mathrm{R} \$ 40,00$ por dia", renda que lhe permite sustentar a si própria e à criança.
Há aqui um jogo no qual a vulnerabilidade e o território, mas também a segurança, fazem operar a política. Nesse jogo, o território não é entendido como espaço onde a vida acontece, mas como exigência de fixação em uma localização geográfica qualquer. Portanto, ser artista de rua é tomado como condição de ameaça, pois não permite a fixação exigida para definir a condição de cliente de um ou outro equipamento da assistência. Além disso, o território, assim re-definido, ao invés de permitir acompanhar os diferentes modos de relação com os espaços, serve para um exame/punição da não fixação, em que se somam o banimento da mãe daquele espaço e o afastamento da criança da convivência familiar. Como produto dessa modalidade de operacionalização, mais do que impedir o acesso à política, promovemos o afastamento entre os agentes da assistência e a população que dela poderia beneficiar-se. A ironia é que esse afastamento decorre justamente de certa definição da vulnerabilidade e da segurança da criança.

Temos, então, duas linhas de ação que se interpenetram: uma avalia a mãe a partir de sua fixação (ou não) no território, e outra avalia a criança a partir de sua vulnerabilidade e segurança. A mãe-artista não se torna alvo da política pela sua condição de vulnerabilidade, mas pela não fixação no território; ao mesmo tempo, é dessa sua condição que decorre a avaliação de vulnerabilidade e risco da criança. Essa dupla vetorização de montagem/desmontagem dá-se no interior da própria política, em que território e vulnerabilidade operam a partir de lógicas diferentes: a proteção da criança faz-se pelo monitoramento das zonas de risco, e essa mesma proteção desmonta-se no entendimento de que a não fixação da mãe no território produz o risco.

Dessa forma, podemos pensar que a incorporação das noções de risco e vulnerabilidade às políticas de saúde e assistência catalisa a releitura da questão social e da própria concepção de direito: ao mesmo tempo em que renuncia à intervenção em prol do indivíduo, a política dissemina em todo o corpo social a sensação de que risco e vulnerabilidade são fenômenos associados, servindo de munição para o controle e a gestão de grupos que alegadamente ameaçam a coesão social (Roberto, 2018). Fugindo da padronização das biografias (Beck, 2001), dadas sua vinculação tênue com o trabalho e sua condição nômade, a mãe-artista é vista como um risco e, por isso, como alguém que merece ser tornado alvo da 
política, que anuncia a assistência, mas incorpora ditames da segurança. Em outras palavras, a jovem encarna, na sua biografia fora do padrão, um risco à coesão social.

Ainda, considerando a organização territorial das políticas em questão, podemos inferir que o controle que elas promovem opera também na dimensão espacial. É a dimensão espacial que permite a distribuição capilarizada e múltipla das estratégias que visam à ordem e ao controle. Essa capilarização faculta e induz processos de montagem e desmontagem no interior da própria política, na medida em que o risco e a vulnerabilidade alargam e transformam as conexões com o território e, com isso, a própria mecânica pela qual a política opera.

Nesse sentido, o território construído e experimentado pela jovem parece assumir uma dinâmica outra que não a prevista, amarrada e formalizada pela política. Porém, se o território - tal como considerado pela política - não se abre para as múltiplas possibilidades construídas pelos múltiplos indivíduos e para as necessidades daqueles a quem a política se destina, o que se pretende com esse território?

Levando em conta essa interrogação, a partir de agora, buscamos traçar um caminho que não só nos permita pensar as composições do território, como também compreender o modo como o território responde a certos requisitos que a política lhe endereça. A partir do conjunto de visibilidades descrito acima, parece possível afirmar que o território, tal como tem sido operacionalizado nas políticas assistenciais, agencia as relações sociais a partir de uma lógica cujas raízes remetem a práticas sanitárias. Essa afirmação não soa estranha a todos quantos reconhecem que a dimensão espacial acompanhou o desenvolvimento do sanitarismo na história. É preciso reconhecer, porém, que o discurso do risco ultrapassa os limites sanitários, razão pela qual as ações que visam ao controle dos riscos igualmente excedem o sanitarismo. Superado o sanitarismo, é o discurso médico-científico que passa a justificar as intervenções punitivas e institucionalizantes da assistência e da justiça (Foucault, 1999). Dada a importância do conceito de espaço nesta discussão, o esquadrinhamento dos grupos-alvo das ações assistenciais-punitivas almeja alvos bem delimitados (os cortiços e as regiões mais pobres da cidade), para cuja população reservam destino certo (as instituições de sequestro).
Dessa forma, o discurso sobre o risco e a qualificação do que seria um meio insalubre acabam ultrapassando em muito o campo sanitário, passando a designar condutas e comportamentos de determinados sujeitos para quem as tecnologias de controle, quando não a mera punição, são os modos de investimento. O discurso registrado na reportagem do Jornal GGN (Dolce, \& Pina, 2019, Desamparo e preconceito, para. 8) ilustra bem:

Eu não posso nem entrar em um supermercado, não me deixam passar pela porta. É por isso que eu peço para pessoas comprarem comida, em vez de me darem dinheiro. O segurança já percebe quando eu entro e já vai atrás achando que eu vou furtar. Às vezes chegam até a nos levar para a sala de patrimônio, já nos acusando de furto.

A reportagem refere-se a processos de segregação e criminalização de pessoas de antemão qualificadas como perigosas. A qualificação tem se expandido, abrangendo até mesmo aqueles que, sem condições econômicas nem sequer para sobreviver, subtraem a comida que lhes assegura a vida. $O$ furto famélico desaparece do cenário social, subsumido pelo risco:

"Eu tava catando latinhas, já fazia uns dias que eu tava com fome, não encontrei comida nos lixos. Aí eu vi as bolachas na janela, mas eu não arrombei, nem nada, só peguei”, afirmou. Segundo o defensor do caso, o advogado Felipe José Ferreira, o J.R.S e outro morador de rua foram encontrados pela polícia no quarteirão seguinte, sentados na sarjeta enquanto comiam as bolachas. A decisão do TJSC é um dos raros casos em que o princípio famélico foi aceito pela corte (Dolce, \& Pina, 2019).

Aqui a vulnerabilidade não está marcada apenas pela necessidade de buscar alimento, mas também pelo fato de que essas vidas, tornadas visíveis pelo confronto com o poder, emergem como não vidas. Conforme a reportagem, para o segurança, para delegados, para a polícia e, eventualmente, para os juízes criminais, situações como a de J.R.S. colocam em evidência o princípio famélico, mas são taxadas como crime, tornam-se alvo de processo judicial e são comumente punidas em sentença judicial, o 
que fere a Emenda Constitucional no 64/2010 (que introduz a alimentação como um direito social) e o artigo $6^{\circ}$ da Constituição Federal, que define como direitos sociais "a educação, a saúde, a alimentação, o trabalho, a moradia, o lazer, a segurança, a previdência social, a proteção à maternidade e à infância, a assistência aos desamparados" (Brasil, 1988/2017, p. 23). Aqui nos deparamos são apenas com a criminalização da pobreza: trata-se da condenação da necessidade humana, da criminalização da fome. Nessa circunstância, o território funde-se à vulnerabilidade pela via do risco.

Queremos destacar, no entanto, que não se trata de qualquer risco: trata-se de uma concepção de risco dirigida especificamente para certa forma de sobre-viver. A partir do enunciado do Jornal GNN, podemos constatar que não há um "reconhecimento da vida" enquanto "vida a ser vivida" (Butler, 2015), pois o que as políticas assistenciais reconhecem é o território onde outras vidas são vividas, e estas, sim, devem ser protegidas.

O investimento em uma vida em detrimento de outra não diz respeito a um mero jogo biopolítico. A releitura das concepções de território e de vulnerabilidade, operada nesse conjunto de ações, fala menos da lógica biopolítica: ela é imanente à lógica da morte pela morte, da assunção de que há vidas que não merecem ser reconhecidas, pois não são inteligíveis nem qualificáveis. Elas dão forma a um governo pela necropolítica. Neste, não se reconhece que a precariedade deve ser insistentemente investida por políticas sociais, originalmente formuladas com esta exclusiva finalidade. No governo pela necropolítica, o que emerge é a hipervalorização da segurança para a proteção de territórios privados, estes merecedores da qualificação "vulneráveis". A partir da necropolítica, pode-se de fato matar ou fazer morrer, pois a vida famélica não fará falta, "não é passível de luto" (Butler, 2015, p. 45) e está exposta "à não vida desde o início" (Butler, 2015, p. 33).

Expliquemos melhor o caminho que tentamos percorrer. Não estamos defendendo que por lei se assegure furtar ou subtrair alimentos. Não é isso, por certo! O que nossa análise defende é a existência e disponibilidade efetiva de políticas públicas destinadas a acolher o cidadão em situação de extrema vulnerabilidade (como aquele que furta para amenizar a própria fome) ou desprotegido (como a jovem artista de rua e seu filho).
Cabe ressaltar que, na construção de nossos argumentos, a gravidade da narrativa da jovem mochileira/artista é largamente superada pela reportagem dos famélicos, mas sua história permite-nos ver certo conjunto heterogêneo de práticas que anunciam uma política que conjuga vida e morte, na qual ainda há algum investimento em políticas sociais, mesmo que frágil. Essas distintas histórias e tempos permitem-nos considerar, justamente, que as tensões entre políticas de vida e morte no Brasil não são inéditas; porém, nestes últimos anos, intensificou-se uma política de morte, viabilizada pelo desmonte das políticas sociais. Na primeira narrativa aqui relatada, relativa a eventos ocorridos em 2016, é possível entrever elementos que, opacos há poucos anos, emergem com mais clareza no atual cenário brasileiro, em que o desmonte das políticas sociais intensifica as vulnerabilidades, acentua a desproteção e ilumina a ação e os efeitos da necropolítica.

Hoje, deparamo-nos não com o governo de gestão da vida, mas com o governo de gestão da morte pela morte: a governamentalidade pela necropolítica. No que se refere ao desinvestimento em políticas públicas, não é somente o "deixar morrer" da biopolítica; o desinvestimento em políticas sociais, conjugado à ampliação de investimentos nas políticas de segurança, possibilita identificar outra racionalidade, aquela que consente ou produz a morte de certos grupos da população que não são considerados como vidas a serem vividas.

Esses agenciamentos de uma não economia da vida permitem compreender como o desmonte das políticas públicas é assimilado como política de governo por segmentos da população que de imediato dela se beneficiam. A discursividade produzida a partir das narrativas examinadas permite levantar a hipótese de que o conceito de vulnerabilidade ganha uma aplicação mais geral, abrangente e perversa ao incorporar o discurso do risco. É visível, nos relatos, que a noção de risco não é eliminada e que seus efeitos, claramente classificatórios e excludentes, mais fluidos, generalizantes e capilarizados, são incorporados à noção de vulnerabilidade.

O risco, atribuído ao indivíduo pela sua mera condição vulnerável, encontra uma via renovada para a individualização dos processos sociais e torna-se passível de "solução" pela padronização das biografias, tendo no trabalho sua principal via (Beck, 2011). Uma massa expressiva de indivíduos, os supranume- 
rários de Castel (2013), não encontra qualquer vinculação com o trabalho e é por isso destituída de valor social, fazendo da vulnerabilidade a condição que antecede a desfiliação social. Como se vê, Beck (2011) e Castel (2013) centram no trabalho a resposta necessária frente à vulnerabilidade: o trabalho é elemento central para a coesão social.

Beck (2011) sustenta que o risco carrega um componente normativo, e Haesbaert (2014) lembra que a crise do modelo de bem-estar social e a precarização social coincidem com o surgimento da organização do espaço com um viés de contenção. Segundo ele, a massa inutilizável pelo capital só pode ser contida na sua expansão e na sua mobilidade. A contenção territorial seria, portanto,

a impossibilidade da reclusão ou do fechamento integral, da clausura ou confinamento. E mesmo que um Estado conseguisse "cercar" todo o seu território, a eficácia desse sistema, nas condições atuais, seria sempre muito relativa, como revela a própria crise do sistema prisional (onde um telefone celular, por exemplo, pode colocar em xeque o controle ali estabelecido): "controle" em relação a que, que tipo de fluxos é efetivamente passível de ser "contido"? Uma das características do termo contenção, e que justifica sua aplicabilidade, hoje, é que ele dá conta, justamente, do caráter sempre parcial, provisório e paliativo do fechamento, ou melhor, do efeito-barragem que cria através das tentativas de contenção dos fluxos - que, contidos por um lado, acabam por encontrar outro "vertedouro" por onde possam fluir (Haesbaert, 2014, p. 32).

É neste panorama, do Brasil dos séculos XX e XXI, que o celeiro das novas políticas de seguridade social vai se construindo, incorporando os conceitos de vulnerabilidade e território, mas também o de risco. Fica claro que, apesar da conotação cidadã da nova Constituição, e valendo-se dela, estes conceitos vêm responder à necessidade de novas estratégias de controle e organização do poder. A territorialização da saúde por meio da ampliação de serviços e a proximidade espacial (e social) têm, à primeira vista, o intuito de promover o acesso aos serviços de saúde, principalmente aos grupos em vulnerabilidade. Da mesma forma, a assistência ocupa-se dos territórios onde a vulne- rabilidade toma corpo em proporções ampliadas, com o intuito de promover o acesso dos indivíduos às demais políticas de seguridade. Ambas as políticas se ocupam, portanto, da coesão social - mas o que é produzido nas entrelinhas dessa montagem: o acesso ou/e a contenção? E mais: parece que o desmonte dessas políticas também incide de forma territorialmente localizada. Sendo assim, a que correspondem os processos de desmontagem?

\section{Desmonte do que e para quem: as descomposições em curso no/pelo território}

Os cortes no Programa Saúde da Família, previstos para o ano que vem, vão ser maiores nas regiões mais pobres da cidade, contrariando o que a prefeitura havia prometido. [...] Nenhuma área da cidade será poupada, mas os cortes não serão uniformes. A população da Zona Oeste, uma das regiões mais carentes da cidade, onde os hospitais públicos enfrentam uma grave crise, será bastante afetada. As 15 Clínicas da Família e os dez centros municipais da AP 5.3 - que reúne Santa Cruz, Paciência e bairros vizinhos vão perder $\mathrm{R} \$ 58$ milhões no ano que vem, o que representa $32,5 \%$ do orçamento (Rodrigues, \& Resende, 2018, p. 14).

Este trecho, extraído de uma reportagem do ano de 2018 sobre os cortes na política de Saúde no município do Rio de Janeiro, traz alguns elementos para pensarmos o desmonte territorialmente localizado. Primeiro, na dimensão mais clara do desmonte, está a redução do orçamento global destinado às áreas programáticas (AP). Em seguida, chama atenção a escolha das áreas a serem priorizadas nos cortes de financiamento: as regiões mais pobres da cidade, cujo contingente de equipamentos de saúde já enfrenta limitações. Trata-se de evidente contradição com um dos princípios fundamentais do Sistema Único de Saúde (SUS), a equidade, que institui exatamente o inverso do que essa opção pelo corte nas áreas mais pobres realiza: o princípio da equidade considera a igualdade a partir das desigualdades, ou seja, os territórios em situação de desvantagem no acesso à saúde, bem como em condição de maior vulnerabilidade, são justamente aqueles a serem priorizados na consolidação do direito. 
Trazemos novamente Castel (2013) para nomear estes grupos: os vulneráveis são aqueles que constituem a franja social que ameaça a coesão social não só pela sua quantidade, mas pela ausência de valor que agregam nas trocas sociais. Eles oscilam entre a possibilidade de exclusão, ou de inclusão. O desmonte nos moldes anunciados acima incide diretamente na diminuição de possibilidades do seu trânsito, fixando-os de forma cada vez mais contundente nas zonas de vulnerabilidade para, finalmente, fabricar sua desfiliação.

Nesse sentido, o desmonte da política brinca com a visibilidade desses grupos, em uma espécie de luz e sombra. Isto é, enquanto se coloca a sombra nos direitos "conquistados" até então por meio do desmonte concreto das políticas sociais, e à medida que se escolhe fazer a desmontagem em territórios específicos, coloca-se luz sobre outros aspectos desses grupos. A visibilidade, portanto, dá-se por outra dimensão, que não a dos direitos. O território e a vulnerabilidade são costurados por outras relações. Não são os territórios que, na ausência de certas condições, se caracterizam como vulneráveis, mas os indivíduos que neles habitam, e em razão da ameaça que representam. Diante do desmonte das políticas que possibilitariam maior trânsito desses grupos nas zonas sociais, tem-se como consequência a montagem de outras respostas, desta feita, ao risco representado pelos supranumerários.

Contudo, agora gostaríamos de percorrer um caminho que nos mostra que aquilo que o jogo democrático permite visibilizar como certos "avanços", tomados como grandes estratégias biopolíticas de estabilidade para as políticas públicas, não passam de "avanços frágeis".

O que queremos dizer com "avanços frágeis"? Vejamos a reportagem de Albuquerque (2018), que traz a seguinte manchete: "Investimento em segurança pública aumentou 6,9\%, diz levantamento: Apesar do aumento, País bateu recorde de mortes violentas em 2017". De acordo com a notícia, bem como com o $12^{\circ}$ Anuário Brasileiro de Segurança Pública 2018 (Fórum Brasileiro de Segurança Pública, 2018), em 2017, o Brasil investiu 0,8\% a mais do que $2016 \mathrm{em}$ segurança pública, percentual ainda reduzido quando comparado ao de outros países e que poderá ser ainda menor em futuro próximo se levarmos em consideração o congelamento do teto de gastos.
Mas a questão que nos toca neste instante é a relação desse investimento em segurança com certas racionalidades de governo, pois há aqui um aumento relativo nos gastos - como aborda a reportagem de Calegari (2018), intitulada "Para onde vai o dinheiro de segurança pública no Brasil: Roraima e Rio de Janeiro lideram com os maiores investimentos per capita em segurança, mas isso não significou fim da violência”. Dessas materialidades, emergem certas zonas de visibilidade e dizibilidade: as materialidades mencionadas até aqui criam condições para desenharmos uma racionalidade de governo: ampliam-se os investimentos, principalmente aqueles direcionados ao aumento do policiamento, mas, estranhamente, não se constata redução da violência; pelo contrário: verifica-se um "crescimento de $21 \%$ de morte por intervenções policiais" (Fórum Brasileiro de Segurança Pública, 2018). Acrescentem-se a isso as considerações de Albuquerque (2018):

[...] o Brasil está aplicando um modelo de segurança pública que é desatualizado, da primeira metade do século passado, com uma legislação que regula as polícias anterior à Constituição de 1988. "A legislação que regula a Polícia Militar é de 1983, o inquérito policial que determina a forma como as polícias Civil e Federal atuem e registrem o fato é de 1871 e os Códigos Penal e de Processo Penal são dos anos 1940. A própria Lei de Execução Penal é de 1984", explicou.

Dessa forma, ao mesmo tempo em que há investimento na segurança pública - em termos de ampliação do policiamento e das intervenções policiais -, verificam-se o aumento da violência e a preservação de um modelo de segurança pública apoiado em legislações anteriores àquela nomeada de Constituição Cidadã. Montagem de um lado, desmonte de outro.

As táticas e os indicadores de segurança são defendidos por certa narrativa que apregoa a busca da estabilidade das políticas de segurança pública. No entanto, o que se produz são "avanços frágeis" que não efetivam a segurança; antes, destinam-se a enfrentar o vazio produzido pelo desmonte micropolítico das políticas sociais. O investimento na segurança parece traduzir, de fato, uma opção pelo controle (e extermínio) de segmentos marginalizados política, econômica e socialmente, em nome da 
proteção de outros grupos. Tomamos esses acontecimentos micropolíticos como indícios da fragilização das políticas sociais e da adesão a uma racionalidade necropolítica. A necropolítica opera, nesse sentido, como um investimento na morte, em vidas matáveis (Mbembe, 2016).

É nesse contexto que, concomitantemente ao desinvestimento nas políticas de assistência e saúde em determinados territórios, tem-se um hiperinvestimento na segurança. É de conhecimento público que territórios vulneráveis, como, por exemplo, as favelas, são alvo de ações incessantes das forças de segurança. Estes territórios são os mesmos que, em momentos de cortes de despesas, são escolhidos para terem seus equipamentos sociais usurpados. Tem-se como nova produção não mais o encarceramento em massa (que, nos moldes das instituições de sequestro, evidenciam as tecnologias disciplinares de poder), mas o extermínio autorizado e legitimado em determinados territórios. A desmontagem é de vidas desqualificadas, tornadas vidas matáveis: território e vulnerabilidade operam justamente como justificativa de extermínio, e não de acesso à cidadania e diminuição de iniquidades sociais (Mbembe, 2016).

Para Haesbaert (2014), a biopolítica desdobra-se na generalização do controle, quando passa a perder o poder sobre a vida e a generalizar a morte. Parte deste funcionamento é a proliferação de todo tipo de risco, incerteza e insegurança, cujos efeitos incidem também na organização espacial. Os limites espaciais também são "generalizados" e perdem precisão, tal como o processo de globalização neoliberal. Como efeito, segundo o autor, tem-se o aumento do grau de descontrole e imprevisibilidade dos territórios. Essa imprevisibilidade, associada ao risco, acaba por encaminhar estratégias necropolíticas, visto que, do potencial de risco, se conformará o risco efetivo - quando em jogo a segurança, em detrimento da proteção. Nesse cenário, o território, que antes abrigava vulnerabilidades, será a zona de ameaça-e assim será tratado.

\section{Juntando as peças da desmontagem}

É importante destacar que este texto não tem o objetivo de, a partir da identificação de estratégias de controle no interior das políticas de saúde e assistência, atacá-las. Elas guardam enorme relevância democrática. Nosso intuito aqui pode ser descrito como um esforço em descrever a complexidade de peças e linhas de força que, atualmente, nos permitem entrever as fragilidades democráticas frente ao desmonte da proteção social e sua aproximação de modelos necropolíticos. Nesse sentido, a defesa das políticas e o reconhecimento de sua importância para condições igualitárias e dignas, principalmente para a população pobre, não podem ser ingênuos a ponto de acreditar que elas se sustentam por si mesmas no curso do jogo democrático.

Afastando ingenuidades, colocamos em questão neste texto a via pela qual as políticas sociais têm perdido valor de proteção para a população pobre ou vulnerável e, por outro ângulo, a lógica que se vale de desmonte para somar ou perpetuar novas tecnologias de poder, que por sua vez intensificam a desproteção e multiplicam as vidas matáveis. A vulnerabilidade e o território tornam-se, assim, estratégias de uma necropolítica, e não propriamente de uma biopolítica, na medida em que permitem a circunscrição e localização do perigo/risco, que pode e deve ser exterminado. Uma política de morte desprotege e torna os efeitos da desproteção elementos a serem matáveis. O que fica patente, no círculo vicioso que identificamos, é que o desmonte das políticas de seguridade social assume diferentes dimensões, cuja variação visa também a diferentes respostas.

Como já dissemos, a formulação original das políticas de saúde e assistência é fruto de uma história de lutas, montagens e desmontagens. No entanto, reconhecemos que o mínimo de estabilidade daquilo que propõem os documentos normativos depende de certas condições de possibilidade. Não podemos desvincular estas condições do momento histórico e político no qual elas surgiram de forma mais potente: no país pós-ditadura, que se esforçava pelo estabelecimento de suas bases democráticas. Entretanto, o que se seguiu foi uma intensa luta, que se dá ainda nos dias de hoje, para que essas bases de fato se consolidem.

Assim, a primeira dimensão de desmonte identificada neste texto dá-se no interior das próprias políticas. Há um elemento positivo aqui: ao tornarem-se objeto de disputa, elas evidenciam sua relevância no jogo democrático, relevância diretamente proporcional às forças que tentam destituí-las. Essa destituição, ou desmonte, tem sido operada pela redução de financiamento e pelo planejamento e implementação dos equipamentos de maneira anômala. Entendemos que, mediante a anunciação de 
que há um esforço democrático, elas se constituem como importante instrumento para pôr em movimento exatamente o seu contrário: afinal, o que significaria, se não isso, o fato de o SUS possuir atualmente mais da metade do seu financiamento pelo setor privado? Não é exatamente o oposto do que deveria ser o próprio SUS? Mas, como fazer isso de forma "democrática", se não por meio dele mesmo? Nesta dimensão, os conceitos de território e vulnerabilidade encarnam importantes vetores para a não consolidação das políticas que lhes dão corpo, viabilizando estratégias de controle da população pobre de forma atualmente mais necropolítica do que biopolítica - pois, mais do que deixar morrer, passa a contar no jogo um fazer morrer.

Ao lançarmos mão desses conceitos, queremos produzir uma nova visibilidade: a dos territórios vulneráveis, onde se localizam os grupos que alegadamente ameaçam a coesão social. Ali, o controle ocorre tanto no nível micropolítico - na individualização das questões sociais e na atribuição de responsabilidade do sujeito pelo seu próprio destino, pela não vinculação ao trabalho, etc. - quanto no nível populacional - na identificação dos "territórios" cujas condições colocam seus habitantes em situação de vulnerabilidade, a qual, ironicamente, deriva da própria desproteção do Estado. Em qualquer uma dessas escalas, no entanto, o que está em jogo é o controle do indivíduo pobre, identificado como fonte de risco e perigo ao restante do corpo social. Desse modo, a não efetivação das políticas assume uma eficácia importante: mediante sua não consolidação, disfarçada de tentativa fracassada de efetivação, acaba se produzindo a demanda de outras respostas. Finalmente, em res- posta a essa "nova" demanda, outras estratégias de poder passam a legitimar-se.

É neste ponto, na dimensão do desmonte que viabiliza uma remontagem, que reconhecemos o lugar das políticas de segurança e o investimento em uma tecnologia de poder necropolítica, em detrimento de uma biopolítica. O desmonte assume outra dimensão: o investimento descarado em um Estado que mata em detrimento da seguridade social, só é possível pela comprovação do fracasso dessas políticas de seguridade. $O$ desmonte de dentro para fora acaba criando condições de possibilidade para que novas respostas surjam, e, finalmente, as políticas sociais de nossa recente democracia vão perdendo cada vez mais seu lugar no jogo. Não há mais necessidade do controle travestido de políticas sociais: o Estado já tem legitimado que, em determinados territórios, o uso de outras estratégias é necessário. Tais estratégias são o extermínio das vidas matáveis.

No entanto, ainda que o cenário não seja favorável para os campos que acreditamos ser imprescindíveis para a consolidação da democracia, não carecemos de lembrar que as desmontagens sempre fizeram parte do jogo e que, assim como aponta Foucault sobre as possibilidades de resistência, sempre existentes, novas montagens também são resultado da disjunção de peças. Dessa maneira, sem a intenção de fechar uma conclusão sobre esse processo dinâmico, complexo e multifacetado, buscamos pôr o foco em algumas das suas faces e peças, com o intuito de, a partir delas, contribuir com uma provocação necessária para que o jogo prossiga: qual a potência de criação na atual desmontagem das peças democráticas?

\section{Referências}

Albuquerque, F. (2018, 9 agosto). Investimento em segurança pública aumentou 6,9\%, diz levantamento. [Website Agência Brasil]. Recuperado de http://agenciabrasil.ebc.com.br/geral/noticia/2018-08/investimento-em-seguranca-publica-aumentou-69-diz-levantamento

Beck, U. (2011). Sociedade do risco: Rumo a uma outra modernidade. São Paulo, SP: Editora 34.

Bernardes, A. G., \& Guareschi, N. M. F. (2008). Direito à vida: Cidadania e soberania. Fractal Revista de Psicologia, 20(1), 149-164. https://doi.org/10.1590/S1984-02922008000100016

Brasil. (2008). Ministério do Desenvolvimento Social e Combate à Fome. CapacitaSuas SUAS: Configurando os eixos de mudança (Vol. 1). Brasília, DF: Instituto de Estudos Especiais da Pontifícia Universidade Católica de São Paulo.

Brasil. (1988/2017). Constituição da República Federativa do Brasil :Atualizada até a EC n. 97/2017. Brasília, DF Supremo Tribunal Federal. Recuperado de http://www.stf.jus.br/arquivo/cms/legislacaoConstituicao/ anexo/CF.pdf

Butler, J. (2015). Quadros de guerra: Quando a vida é passível de luto? Rio de Janeiro, RJ: Civilização Brasileira. 
Calegari, L. (2018, 5 março). Para onde vai o dinheiro de segurança pública no Brasil Roraima e Rio de Janeiro lideram com os maiores investimentos per capita em segurança, mas isso não significou fim da violência. [Website Exame]. Recuperado de https://exame.abril.com.br/brasil/para-onde-vai-o-dinheiro-de-seguranca-publica-no-brasil/

Castel, R. (2013). A metamorfose da questão social: Uma crônica do salário. Petrópolis, RJ:Vozes.

Cruz, L. R., \& Hillesheim, B. (2016). Vulnerabilidade social. In R. M. C. Fernandes, \& A. Hellmann (Orgs.), Dicionário crítico: Política de assistência social no Brasil (pp. 300-302). Porto Alegre, RS: UFRGS.

Dolce, J. \& Pina, R. (2019, 13 março). Famélicos: A fome que o Judiciário não vê. [Wesite Jornal GGN]. Recuperado de https://jornalggn.com.br/judiciario/famelicos-a-fome-que-o-judiciario-nao-ve/

Emenda Constitucional No 95, de 15 de dezembro de 2016. Altera o Ato das Disposições Constitucionais Transitórias, para instituir o Novo Regime Fiscal, e dá outras providências. Diário Oficial da União, 16 de dezembro de 2016.

Fórum Brasileiro de Segurança Pública. (2018). 12 Anuário brasileiro de Segurança Pública, São Paulo. Recuperado de http:// www.forumseguranca.org.br/wp-content/uploads/2019/02/Anuario-2019-v6-infogr\%C3\%A1fico-atualizado.pdf

Foucault, M. (1999). Em defesa da Sociedade: Curso no Collège de France (1975-1976). São Paulo, SP: Martins Fontes.

Foucault, M. (2003). Ditos \& escritos IV: Estratégia, saber-poder. Rio de Janeiro, RJ: Forense Universitário.

Gondim, G. M. M., \& Monken, M. (2018). O uso do território na Atenção Primária à Saúde. In M. H. M. Mendonça, G. C. Matta, R. Gondim, \& L. Giovanella (Orgs.), Atenção primária à Saúde no Brasil: Conceitos, práticas e pesquisa (pp. 143-76). Rio de Janeiro, RJ: Fiocruz.

Haesbaert, R. (2014). Contenção territorial: "campos” e novos muros. Boletín de Estudios Geográficos, (102), 25-45.

Haraway, D. (1995). Saberes localizados: A questão da ciência para o feminismo e o privilégio da perspectiva parcial. Cadernos Pagu, (5), 7-41.

Hillesheim, B., \& Cruz, L. (2008). Risco, vulnerabilidade e infância: Algumas aproximações. Psicologia \& Sociedade, 20(2), 192-199. https://doi.org/10.1590/S0102-71822008000200006

Hüning, S. M., \& Scisleski, A. C. C. (2018). A noção de vulnerabilidade da Política Nacional de Assistência Social. In M. P. Cordeiro, B. Svartman, \& L.V. Souza. (Orgs.), Psicologia na assistência social: Um campo de saberes e práticas (Vol. 1, pp. 133-143). São Paulo, SP: Instituto de Psicologia da Universidade de São Paulo.

Lei No 8.069, de 13 de julho de 1990. Dispõe o Estatuto da Criança e do Adolescente e dá outras providências. Diário Oficial da União, 16 de julho de 1990.

Mbembe, A. (2016). Necropolítica. Arte \& Ensaios, (32), 122-151.

Noguera, R. (2018). Dos condenados da terra à necropolítica: Diálogos filosóficos entre Frantz Fanon e Achille Mbembe. Revista Latinoamericana do Colégio Internacional de Filosofia 1(3), 59-73.

Resolução do CNAS No 130, de 15 de julho de 2005. Aprova a Norma Operacional Básica da Assistência Social - NOB SUAS. Diário Oficial da União, 25 de julho de 2005.

Roberto, N. L. B. (2018). Intersecções entre saúde mental e socioeducação: a intersetorialidade como fio condutor (Dissertação de mestrado). Instituto de Psicologia, Universidade Federal do Rio de Janeiro, Rio de Janeiro, RJ, Brasil.

Rodrigues, R., \& Resende, D. (2018, 11 outubro). Corte será maior em áreas pobres. O GLOBO, Caderno Rio, p. 14.

\section{Camilla Fernandes Marques}

Doutoranda em Psicologia pela Universidade Católica Dom Bosco. Campo Grande - MS. Brasil.

E-mail: camilla.fmt@hotmail.com

https://orcid.org/0000-0003-1305-9709

Nathalia Leardini Bendas Roberto

Docente na Universidade Estácio de Sá. Rio de Janeiro - RJ. Brasil.

E-mail: nathalialeardini@gmail.com

https://orcid.org/0000-0002-1745-3079 
Hebe Signorini Gonçalves

Docente e Pesquisadora do Programa de Pós-Graduação em Psicologia da Universidade Federal do Rio de Janeiro.

Rio de Janeiro - RJ. Brasil.

E-mail: hebe@globo.com

(iD) https://orcid.org/0000-0003-1688-9927

Anita Guazzelli Bernardes

Docente e Pesquisadora do Programa de Pós-graduação em Psicologia da Universidade Católica Dom Bosco.

Campo Grande - MS. Brasil.

E-mail: anitabernardes1909@gmail.com

(iD) https://orcid.org/0000-0003-4742-6036

Endereço para envio de correspondência:

Av. Tamandaré, 6000, Jardim Seminário. CEP: 79117-900. Campo Grande - MS, Brasil.

Recebido:24/06/2019

Aceito: 22/07/2019

Received:06/24/2019

Approved: 07/22/2019

Recibido:24/06/2019

Aceptado: 22/07/2019

Como citar: Marques, C. F., Roberto, N. L. B., Gonçalves, H. S., \& Bernardes, A. G. (2019). O que significa o desmonte? Desmonte do que e para quem?. Psicologia: Ciência e Profissão, 39(n.spe 2), 6-18.

https://doi.org/10.1590/1982-3703003225552

How to cite: Marques, C. F., Roberto, N. L. B., Gonçalves, H. S., \& Bernardes, A. G. (2019). What does dismantling mean? Dismantling of what and for whom?. Psicologia: Ciência e Profissão, 39(n.spe 2), 6-18. https://doi.

org/10.1590/1982-3703003225552

Cómo citar: Marques, C. F., Roberto, N. L. B., Gonçalves, H. S., \& Bernardes, A. G. (2019). ¿Qué significa el desmontaje? ¿Desmontaje qué y para quién?. Psicologia: Ciência e Profissão, 39(n.spe 2), 6-18.

https://doi.org/10.1590/1982-3703003225552 